ZOOLOGIA 28 (3): 403-406, June, 2011

doi: $10.1590 /$ S1984-46702011000300015

\title{
A new species of Seira (Collembola: Entomobryidae: Seirini) from the Northeastern Brazilian coastal region
}

\author{
Bruno Cavalcante Bellini ${ }^{1} \&$ Douglas Zeppelini
}

\author{
${ }_{1}^{1}$ Programa de Pós-graduação em Sistemática e Evolução. Centro de Biociências, Departamento de Botânica, Ecologia e \\ Zoologia, Universidade Federal do Rio Grande do Norte. Campus Natal, 59072-970 Natal, RN, Brazil. \\ E-mail: entobellini@gmail.com \\ ${ }^{2}$ Laboratório de Sistemática de Collembola e Conservação. Centro de Ciências Biológicas e Sociais Aplicadas, Universidade \\ Estadual da Paraíba. Campus V, 58020-540 João Pessoa, PB, Brazil.
}

\begin{abstract}
Seira Lubbock, 1869 is the most speciose genus of Collembola in Brazil. Herein, we describe and illustrate a new species of Seira, Seira ritae sp. nov., collected in João Pessoa, state of Paraíba, Brazil, in an urban seaside area. The new species shows many similarities with S. mendoncea Bellini \& Zeppelini, 2009 especially in what concerns the dorsal distribution of the macrochaetae of the head, the metathorax, and the first three abdominal segments. However, the two species can be distinguished by the chaetotaxy of the mesothorax and abdominal segment IV. The type locality of the species probably indicates some level of natural resistance to the impacts associated with human activities.
\end{abstract}

KEY WORDS. Brazilian collembolan diversity; chaetotaxy patterns; Entomobryomorpha; Seirinae; systematics.

Entomobryidae is the largest family of Collembola (HopkIN 1997, Soto-Adames et al. 2008, Bellinger et al. 1996-2011). Seira Lubbock, 1869 is a predominantly tropical genus of Entomobryidae, with almost 200 described species worldwide (BARRA 2010, Bellinger et al. 1996-2011). In Brazil, Seira is the most speciose genus of Collembola, with 25 described species (Abrantes et al. 2010, Bellini et al. 2010). Specimens of Seira spp. are very common in this country in practically all kinds of environments (ABRANTEs et al. 2010). This condition is especially true in Northeastern Brazil, where at least 15 species were reported and eight of them were described within the last five years (Zeppelini \& Bellini 2006, Bellini \& Zeppelini 2008a,b, 2009a,b, Beluini et al. 2009, 2010).

The morphology of species of Seira is quite similar to species of other derived genera of Entomobryidae, such as Entomobrya Rondani, 1861 and Lepidocyrtus Bourlet, 1839. However, species of Seira can be distinguished from them by the presence of a falcate mucro, eight or seven lenses on each eyepatch, and yellow or brown round scales covering the dorsum of the head, body, and the first segments of antennae, legs, and furca (Christiansen \& Bellinger 2000, Barra 2004a,b).

Herein, we describe a new species of Seira from the Northeastern Brazilian coastal area. The specimens were found associated to sand dunes and collected using Berlese-Tullgren funnels. The chaetotaxic system used to describe the disposition of dorsal macrochaetae follows that of CHRISTIANSEN \& BELLINGer (2000), which was modified from JACQUeMART (1974).
Type material is deposited in the Museu Nacional, Universidade Federal do Rio de Janeiro (CM/MNRJ).

\section{TAXONOMY}

\section{Seira ritae sp. nov.}

Figs 1-11

Description. Habitus typically entomobryid (Figs 1 and 2). Measurements of the holotype: antennae length $0.23 \mathrm{~mm}$; head length $0.2 \mathrm{~mm}$; body length $0.81 \mathrm{~mm}$; furca length $0.24 \mathrm{~mm}$. Total body length of holotype (head + body) $1.01 \mathrm{~mm}$. Rate between antennal length and cephalic diagonal 1.21. Color of fixed specimens pale white, with light blue pigment covering antennae and dark blue pigment covering front head and eyepatches (Fig. 1). Color of mounted specimens pale white to pale yellow with light blue pigment covering antennae and sometimes the legs and dark blue pigment covering eyespatches and front head. Brown apically rounded scales covering antennae I and II, basal half of antennae III, basal third of antennae IV, head, thorax, abdomen, all leg segments, manubrium and dens. Collophore without scales. Fourth antennal segment not annulated, with single apical bulb, without pin setae (Fig. 3). Eyepatches oval, with largest lens being $\mathrm{G}$ and smallest lens being $\mathrm{E}$, with four interocular feathered setae (Fig. 4). Pre-labral setae feathered and labral setae smooth. Labial triangle seta $\mathbf{r}$ reduced and M1, M2, E and L feathered (Fig. 5). Trochanteral organ V-shaped with approximately 17 

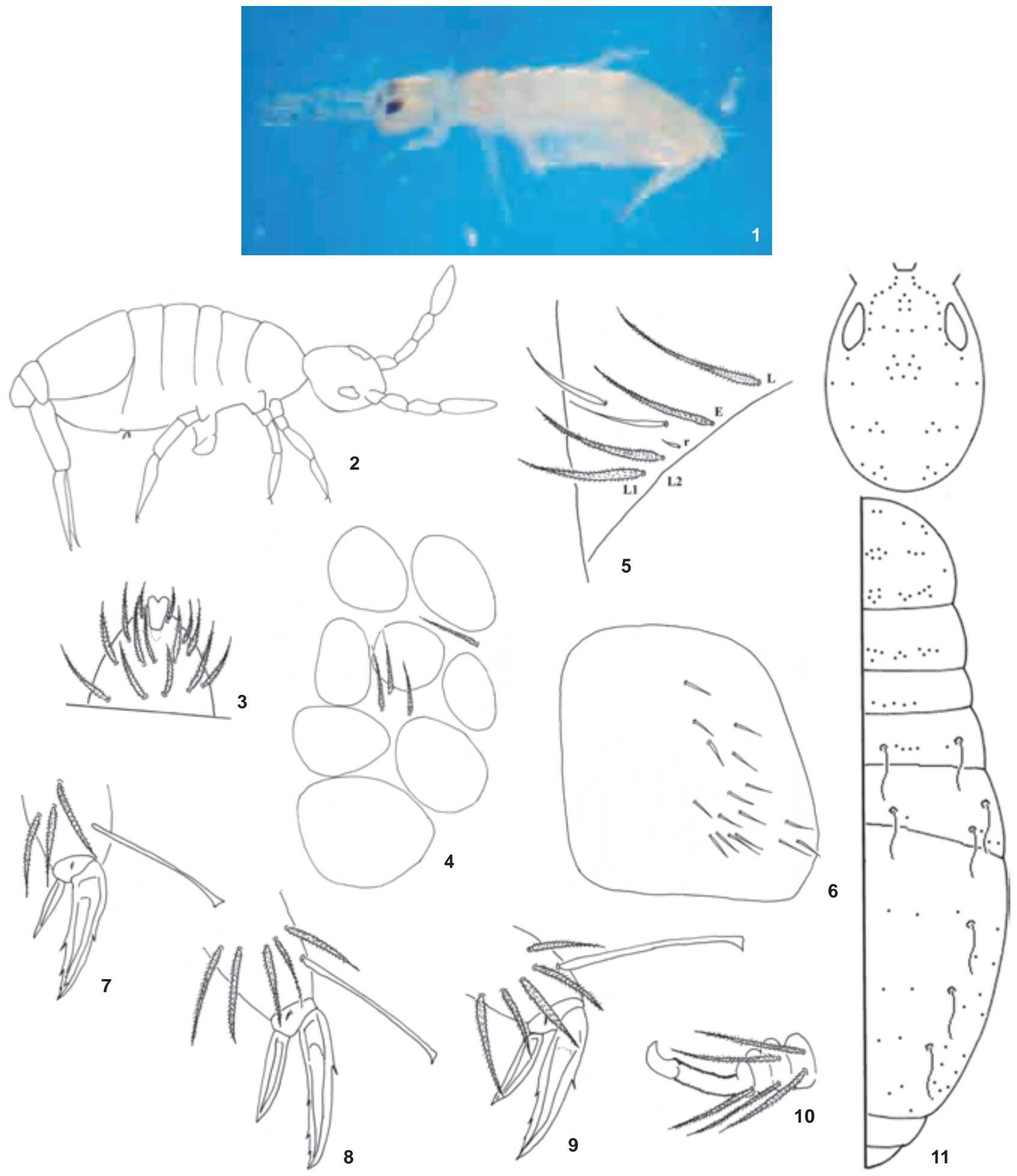

Figures 1-11. Seira ritae sp. nov.: (1) habitus of a fixed specimen showing body pigmentation; (2) habitus; (3) apical bulb of the $4^{\text {th }}$ antennal segment; (4) lenses of the right eyepatch; (5) setae of the labial triangle; (6) trochanteral organ; (7) first foot complex; (8) second foot complex; (9) third foot complex; (10) distal dens and mucro; (11) dorsal macrochaetae distribution. 
spine-like setae (Fig. 6). Pro-, meso- and metaungues with four inner teeth, one major pair at base and two minor unpaired teeth at apex (Figs 7-9). Unguiculi acuminate with smooth edges (Figs 7-9). Tenent hair slightly serrate and capitate. Venter of manubrium with $4+4$ subapical setae. No spine-like setae on manubrium. Mucro typically falcate (Fig. 10). Dorsal macrochaetae distribution on head and body as in figure 11.

Type material (MNRJ). Holotype female, Brazil, Paraíba, João Pessoa, Praia do Bessa. 03-III-2009. Melo, C.F. leg. Paratypes: 3 females, 1 male and 2 juveniles, same data as holotype.

Etymology. Seira ritae sp. nov. was named after Dr. Rita Mascarenhas, who develops her research in the type locality of the species.

Remarks. The closest species to $S$. ritae sp. nov. appears to be $S$. mendoncea Bellini \& Zeppelini, a taxon also reported from the state of Paraíba (BeLLini \& Zeppelins 2008b). These taxa share similar patterns of dorsal macrochaetae distribution on all cephalic regions (except posterior region 6), metathorax, and abdominal segments I, II and III (in this last one, there are extra setae on region B in $S$. ritae sp. nov.). Both species also have similar feet complexes, labial triangle chaetotaxy, and same number of interocular setae (even though they are in different positions in the two species). However, these last three morphological conditions are recurrent among many species of Seira (Christiansen \& Bellinger 2000).

Seira ritae sp. nov. can be distinguished from $S$. mendoncea and other species of Seira by an unique combination of the dorsal chaetotaxy of mesothorax and abdominal segment IV. In these two segments, almost all regions have different numbers and positions of macrochaetae in $S$. ritae sp. nov. and $S$. mendoncea. Seira ritae sp. nov. also has $4+4$ subapical setae on the manubrium, whereas $S$. mendoncea has $5+5$. Finally, while $S$. ritae sp. nov. was only found next to the seashore, $S$. mendoncea was reported solely from the Caatinga biome (BELLINI \& ZEPPELINI 2008b).

Seira ritae sp. nov. was collected over sand dunes of "Praia do Bessa", an urban shore area in João Pessoa, capital of the state of Paraíba. This area is located in the Good's biogeographic zone 27 (Good 1974). The specimens were collected near the upper vegetation of sand dunes, during the wet season. The climate of the type locality is 'As', according to Koeppen's system (Коттек et al. 2006), which means that the main climate of the area is equatorial and the precipitation levels indicate a dry summer. The survival of the species in an urban, highly impacted area possibly indicates some level of resistance to major environmental issues, such as air, ground and water pollution, reduction of original vegetation cover, introduction of exotic plants and animals and other ecological harms related to constant human presence.

\section{ACKNOWLEDGEMENTS}

The two authors received grants from CNPq (\#35.0325/ 2010.3 and \#300527/2008-0).

\section{LITERATURE CITED}

Abrantes, E.A.; B.C. Bellini; A.N. Bernardo; L.H. Fernandes; M. C. Mendonça; E.P. Oliveira; G.C. Queiroz; K.D. Sautter; T.C. Silveira \& D. Zeppelini. 2010. Synthesis of Brazilian Collembola: an update to the species list. Zootaxa 2388: 122.

BARra, J.-A. 2004a. Le genre Seira (Collembola, Entomobryidae) du Yémen continental. Zoosystema 26 (2): 291-306.

BARRA, J.-A. 2004b. Springtails of the genus Seira Lubbock, 1869 (Collembola: Entomobryidae) from Socotra Island, Yemen. Fauna Arabia 20: 399-408.

BARRA, J.-A. 2010. Une nouvelle espèce de Seira Lubbock, 1869 (Collembola, Entomobryidae) de Tunisie présentant des caractères sexuels secondaires. Zoosystema 32 (4): 585-593.

Bellinger, P.F.; K.A. Christiansen \& F. Janssens. 1996-2011. Checklist of the Collembola of the World. Available online at: http://www.collembola.org [Accessed: 30/IX/2010].

Beluini, B.C. \& D. Zeppelini. 2008a. Three new species of Seira Lubbock (Collembola, Entomobryidae) from Mataraca, Paraíba State, Brazil. Zootaxa 1777: 44-54.

Bellini, B.C. \& D. Zeppelini. 2008b. A new species of Seira (Collembola: Entomobryidae) from northeastern Brazil. Revista Brasileira de Zoologia 25 (4): 724-727.

Bellini, B.C. \& D. Zeppelini. 2009a. Registros da fauna de Collembola (Arthropoda, Hexapoda) no Estado da Paraíba, Brasil. Revista Brasileira de Entomologia 53 (3): 386-390.

Beluini, B.C. \& D. Zeppelini. 2009b. A new species of Seira Lubbock (Collembola, Entomobryidae), with a key to the species of Paraíba, Brazil. Revista Brasileira de Entomologia 53 (2): 266-271.

Bellini, B.C.; A.P. Pais \& D. Zeppelini. 2009. A new species of Seira Lubbock (Collembola: Entomobryidae) from Brazil with sexually dimorphic legs. Zootaxa 2080: 38-46.

Beluini, B.C.; L.H. Fernandes \& D. Zeppelini. 2010. Two new species of Seira (Collembola, Entomobryidae) from Brazilian coast. Zootaxa 2448: 53-60.

Christiansen, K. \& P. Bellinger. 2000. A survey of the genus Seira (Collembola: Entomobryidae) in the Americas. Caribbean Journal of Science 36 (1-2): 39-75.

Good, R. 1974. The geography of flowering plants. London, Longman Group, $4^{\text {th }}$ ed., $574 \mathrm{p}$.

НоркIN, S.P. 1997. Biology of the Springtails (Insecta: Collembola). Oxford, Oxford University Press, 330p.

JaCquemart, S. 1974. Resultats de la mission Anthropologique Belge au Niger. Collemboles nouveaux du Sahara. Bulletin del I'Institut Royal des Sciences Naturelles de Belgique, Entomologie 40 (6): 1-46.

Kottek, M.; J. Grieser; C. Beck; B. Rudolf \& F. Rubel. 2006. World map of the Köppen-Geiger climate classification updated. Meteorologische Zeitschrift 15 (3): 259-263.

Soto-Adames, F.N.; J.A. Barra; K. Christiansen \& R. Jordana. 2008. Suprageneric classification of Collembola Entomobryomorpha. 
Annals of the Entomological Society of America 101 (3): 501-513.

Zeppelini, D.F. \& B.C. Beluini. 2006. Two Seira Lubbock 1869

Submitted: 25.I.2011; Accepted: 24.IV.2011.

Editorial responsibility: Gabriel L.F. Mejdalani
(Collembola, Arthropleona, Entomobryidae) new to science, with remarkable secondary sexual characters. Zootaxa 1185: 21-35. 